\title{
LA GRAMÁTICA DE LA LENGUA ARÁBIGO-ERUDITA Y SU INFUNDADA ATRIBUCIÓN A PATRICIO DE LA TORRE
}

Por

BRAULIO JUSTEL CALABOZO

En el primer número de esta revista, aparecido en el año 1984, se publicó un breve artículo nuestro que versaba sobre la refundición del Vocabulista de Pedro de Alcalá por Patricio de la Torre, monje escurialense y arabista, que nació en Orgaz (Toledo) en el año 1760, tomó el hábito jerónimo en el monasterio de San Lorenzo en el 1776, pasó a estudiar árabe en los Reales Estudios de San Isidro de Madrid en el 1784, estuvo unos años en Marruecos y murió en el citado monasterio en el año 1819. Allí ofrecíamos éstos y algunos datos más de su biografía y a ellos remitimos ahora al ocuparnos de una obra que se le ha atribuido -en nuestra opinión, erróneamente-: la Gramática de la lengua arábigo-erudita (1).

Ocupa esta obra todo el códice h.IV.4 de la Real Biblioteca Escurialense, del que Julián Zarco Cuevas da la siguiente descripción en su Catálogo:

«334 hojas de papel, foliadas a lápiz con numeración arábiga, de muy buena letra de [I] siglo XVIII o principios del XIX. Caja total: $197 \times 142 \mathrm{~mm}$. Encuadernación en cartón» (2).

La obra comienza directamente con el «Capítulo primero: de los elementos de este idioma. Letras del alfa-beto. Figura de ellas». Carece, pues, de portada, y es solamente en el reverso de la hoja de guarda inicial donde se lee: «Rdo. P. Fr. Patricio de la Torre, monje del Escorial». La letra de esta anotación parece de Félix Rozanski, bibliotecario de El Escorial desde el 29 de septiembre de 1875 hasta el 27 de mayo de 1884 (3), y suponemos que en ella se habrá basado el catalogador para

(1) Véase Sharq al-Andalus 1 (1984), 35-46.

(2) Véase Julián ZARCO CUEVAS, Catálogo de los Manuscritos Castellanos de la Real Biblioteca de El Escorial, t. I, Madrid, 1924, p. 235.

(3) Algunos datos relativos a la labor de este sacerdote polaco en El Escorial pueden verse en nuestro libro: La Real Biblioteca de El Escorial y sus manuscritos árabes. Sinopsis histórico-descriptiva, 2. ${ }^{a}$ ed., Madrid, $1987, \mathrm{pp} .112,113,237$ y 238. 
adjudicar sin reservas la autoría de la obra a Fr. Patricio. A nosotros personalmente nunca nos pareció tan probante dicha anotación, pues entendiamos que aún en el caso de que fuera de mano del propio monje - cosa que no creemos--, podía significar simplemente que el ejemplar era de su uso o propiedad. Pero es que ahora, al examinar más de cerca el manuscrito para elaborar este breve apunte, nos hemos encontrado con algo que entedemos constituye, por sí solo, una seria dificultad en orden a reconocerle a Patricio de la Torre la paternidad de la obra, como vamos a ver.

En su artículo «Arabistas españoles del siglo XIX» (4), Sánchez Pérez le dedica a esta gramática - que considera del toledano- un párrafo de media página. Estima que «se han encuadernado sin orden, en un solo volumen, cuatro cuadernos fragmentarios que debieron de ser borradores de un libro" (5), y expone sumarísimamente el contenido de cada uno de ellos (6).

Por nuestra parte, queremos añadir aquí algunas puntualizaciones, aunque sin descartar el ocuparnos más detenidamente de la obra en otra ocasión.

A pesar de que el códice presenta, a primera vista, una gran homogeneidad en cuanto al formato, papel, número de líneas por página, caligrafía, etc., también se detectan en él algunas anomalías. Además de la foliación a lápiz, que es moderna y que se sucede uniforme e ininterrumpidamente a lo largo de las 334 hojas del códi$\mathrm{ce}$, hay una paginación a tinta - original y de la misma tinta que el texto- que comienza en el folio $187 \mathrm{r}$ con el número 256 y termina en el folio $241 \mathrm{v}$ con el número 365. Más aún, en el folio $242 \mathrm{~V}$ empieza - con el número 1 - otra nueva paginación, también original y a tinta, que termina - con el número 163 - en el folio 323v. Las hojas posteriores no llevan más que la moderna foliación a lápiz. Haciendo caso omiso de algunas hojas o páginas que van en blanco, a estas cuatro secciones coresponden los "cuatro cuadernos fragmentarios» que, según Sánchez Pérez, "se han encuadernado sin orden en un solo volumen» y que ocupan, respectivamente, las hojas siguientes: 1-184, 187-241, 242-323 y 324-334 (7).

Creemos, no obstante, que son dos solamente los cuadernos o conjuntos heterogéneos que se han reunido en este códice. El primero coincidiría con el primero de Sánchez Pérez (folios 1-184), y el segundo abarcaría los tres restantes. Nos fundamos para ello en los pormenores siguientes:

a) Los cuadernillos del códice, que llevan la correspondiente signatura en el ángulo superior izquierdo de su primera hoja, van numerados -en el primer conjunto- con los guarismos 1 al 7 , aunque con alguna omisión y alguna pequeña anomalía; y a partir del folio 187 comienza una nueva numeración, que continúa en los 15 cuadernos restantes.

b) Aunque la letra de ambos conjuntos parece de una misma mano, la del primero es, en general, de mayor tamaño que la del segundo.

\footnotetext{
(4) Publicado en la revista A/-Anda/us 18 (1953), 450-455.

(5) Pág. 452

(6) Págs. 452 y s.

(7) Pág. 453.
} 
c) Lo que Sánchez Pérez llama «tercer cuaderno» (folios 242-323) y que lleva, por epígrafe, «Apéndice o suplemento a la Gramática, en que se anotan algunas particularidades que le faltan», remite, en sus anotaciones a los distintos temas gramaticales, a las páginas en que aquéllos han sido tratados, y tales remisiones resultan exactas en lo que hemos llamado «segundo conjunto», pero no en el «primero». De donde se infiere que los cuadernos segundo y tercero de Sánchez Pérez constituyen un todo homogéneo y se complementan adecuadamente - a pesar de que ese «tercer cuaderno» 0 «apénd;ce» lleve su propia paginación-, mientras que el «cuaderno primero» de Sánchez Pérez, o -lo que es lo mismo- nuestro «primer conjunto», forma claramente grupo aparte, aunque su contenido sí responda, básicamente, a las remisiones del «apéndice». Creemos, por ello, que ese «primer conjunto" debe de diferir muy poco, en el fondo, de la parte de la obra que ha suplantado: probablemente se trata de dos copias cuyas paginaciones no coinciden. Más aún, hay indicios para suponer fundadamente que la copia contenida hoy en día en el códice vendría a ser como una segunda edición, corregida y aumentada, de la anterior. El fundamento para esta hipótesis sería que algunas de las anotaciones del «apéndice» referentes a puntos tratados en el "cuaderno primero" han sido incluidas - a veces casi literalmenteen la actual copia del mismo. Tal es el caso de las anotaciones primera y segunda. La primera (folio 242 v) dice así:

«Pág. 111. Añádase: No tienen los Arabes género neutro. Le suplen con el género

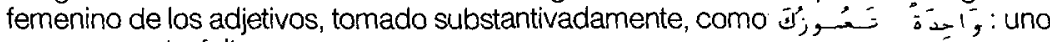
o una cosa te falta».

En el «cuaderno primero» dicha anotación no se encuentra en la página 111 (que sería la hoja 56 r), sino en una nota de las hojas 74 v y 75 r (que equivaldrían a las páginas 158 y 159), donde figura en los siguientes términos:

«Nota: No tienen los Arabes género neutro; lo suplen con el femenino, como v.g.: تُ

La segunda anotación viene formulada en el «apéndice» (folios 242v-243v) como sigue:

«Pág. 137. Añádase: Los Árabes declinan por letras añadidas al fin del tema del nombre o por moción, esto es, con nunación solamente. Por letras, los duales, cua-

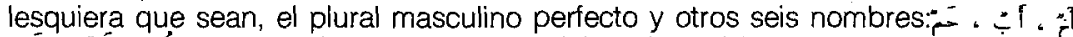
como también las personas del modareo (8) que lleban al fin las letras - is . Por mociones se declina todo singular, el plural fracto femenino y modareo chezmado (9).

Y se añade esta observación:

«No obstante que esta docrina es del sabio Charumi (10), en su gramática árabe, pág. 23, no comprehendo cómo el plural femenino sano y modareo chezmado se declinan por mociones, siendo asi que éste no las tiene y aquél se forma con las letras $=i$ al finm.

(8) Es decir: el mugāarico imperfectivo.

(9) O sea: el mudăric maŷzüm o apocopado.

(10) Se trata, obviamente, del conocido gramático marroquí lbn Aŷurrūm (m. 723/1323), sobre el que puede verse $\left.E\right|^{2}$, III, 719 . 
En el «cuaderno primero», hojas $76 \mathrm{v}-77$ r (que serían las páginas 152-153, y no la página 137), la anotación aparece en la forma siguiente:

«Nota 1. a : Declinan los Árabes por mociones y letras: por mociones declinan el singular, el plural fracto, el plural femenino perfecto y el modareo, con tal que no se le ponga al fin cosa alguna. Declinan por letras el dual, el plural masculino perfecto, estos seis nombres: ${ }^{-i}$ : hermano, ${ }^{-} \bar{c}$ : padre,

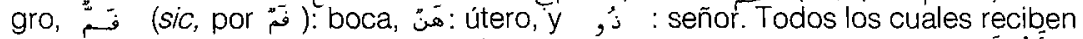
guau en rafa (11), ye en los casos oblicuos (12), y alef en el nasbo (13), como أَ

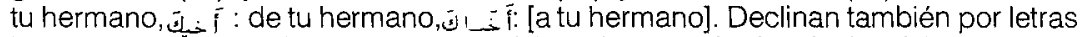
la segunda persona singular femenina del modareo, todas las duales del mismo con sus segundas y terceras plurales masculinas, como se verá en su respectivo tratado».

Ha sido omitida la pertinente observación del «apéndice».

La diferencia entre el número de páginas que parece haber tenido la copia anterior del «cuaderno primero» (255 páginas) y las que tiene la copia actual (267 páginas), podria explicarse, al menos en parte, por el mayor tamaño de la letra de ésta y también por las anotaciones del «apéndice» que le han sido incorporadas.

Aunque falta en el «apéndice» alguna anotación prometida en el cuerpo de la Gramática, creemos que ésta, tal y como actualmente se encuentra en el códice, no está formada por «cuatro cuadernos fragmentarios que debieron ser borradores de un libro", como escribe Sánchez Pérez (14), sino que responde a lo que el autor quiso ofrecernos, aunque le faltó una última lectura para darle la necesaria homogeneidad a la división en libros y en capítulos. Desde luego, si se trata de un borrador, por la presentación no lo parece: es una copia pulcra y nítida.

Los principales puntos tratados en la gramática son, a grandes rasgos, los siguientes: «identidad» (15), «prolación» (16), división y valor númerico de las consonantes; mociones y signos; sílabas y acentos; reglas para leer; el nombre: formación y accidentes (género, número y declinación), pronombres personales, demostrativos y relativos, numerales; el verbo: simple o compuesto (17), trilitero y «quadrilítero», activo y pasivo, sano y enfermo, etc.; partícula, y sintaxis. Tras la sintaxis (folios $190 \mathrm{r}-241 \mathrm{v}$ ) viene el largo «apéndice» con diversas anotaciones y tablas de nombres de acción y de plurales, y un apartado final sobre el «kalām u oración».

En cuanto al título, ya dijimos que, al carecer de portada, no lo lleva. Zarco Cuevas y Sánchez Pérez le dan el de Gramática arábigo-castellana (Zarco escribe «arabigocastellana»). No obstante, en el epigrafe del folio 48v se lee: Gramática de la lengua Arábigo-erudita; en el del folio 129v: «Parte segunda de la Gramática Arábigoerudita»; y en los de los folios 187r y 190r: "Libro Quarto» y «Libro Quinto», respectivamente, «de la Gramática Arábiga». El título sería, pues, uno de los tres siguientes: Gramática de la lengua arábigo-erudita, Gramática arábigo-erudita y Gramática ará-

(11) Es decir: $w \bar{a}$ ) en rafi o nominativo.

(12) O sea: $y \bar{a}$ ) en genitivo.

(13) Es decir: en el nașb o acusativo.

(14) Véase su artículo citado, p. 452.

(15) Se refiere a la naturaleza de las letras del alifato.

(16) Es decir: la pronunciación.

(17) O sea: primitivo o derivado. 
biga. Personalmente nos quedariamos con el primero: Gramática de la lengua arábigoerudita.

Con respecto a la datación del códice, del que Zarco Cuevas escribe -como vimos al comienzo-: «letra de [l] siglo XVIII o principios del XIX», debemos puntualizar que el año exacto de su redacción aparece en un pasaje relativo al valor numérico de las letras árabes (folio 10V), donde el autor dice: «[...] y si se quiere escribir con letras el año en que estamos de $1783,[\ldots]$. El 1783 sería, pues, el año en que se compuso la obra o, al menos, esa primera parte de la misma, parte que, en nuestra opinión sería, como hemos intentado demostrar, posterior al resto de aquélla. Y aquí surge la dificultad con que deciamos haber topado respecto de la autoría, pues estos datos cronológicos plantean un serio problema acerca de ésta.

En efecto, si la obra fue escrita en el año 1783, por una parte Patricio de la Torre no tenía entonces más que 23 años y, por otra -y aquí radica la dificultad más embarazosa-, nos consta que, como queda dicho, no pasó a Madrid a iniciarse en el árabe hasta el año siguiente: ¿cómo pudo, a tenor de esto, ser el autor de una Gramática de la lengua arábigo-erudita?

Personalmente tenemos por seguro que no fue Fr. Patricio quien compuso dicha Gramática; es más, por las averiguaciones que venimos realizando en torno a ella y por algunas que estamos efectuando en torno a otra, que alguien ha dado por anónima y que yace arrinconada en los plúteos de cierta biblioteca de provincia, creemos poder aventurar que las dos son copias de una misma obra y que su autor no es otro que el catedrático de «lengua arábigo-erudita" y profesor de Patricio de la Torre en los Reales Estudios de San Isidro, don Mariano Pizzi y Frangeschi (t 1791), tristemente célebre por su espurio Tratado de las aguas medicinales de Salam-Bir que comúnmente llaman de Sacedón, escrito en lengua árabe por Agmet-Ben-AbDala, médico de Toledo en el año de 1504. Traducido al idioma castellano e ilustrado con varias notas, para su mayor inteligencia [...], publicado en Madrid en 1761 , pero de quien consta que compuso varias gramáticas árabes (18), aunque tal vez no se pueda descartar que otros hayan tenido en ellas más parte que él, como se ha dicho (19).

(18) Sobre ellas puede verse Lucien BOUVAT, «Sur quelques manuscrits de la Société Asiatique relatifs à l'Espagne», Fevue Hispanique 15 (1906), 721-739. En las páginas 738 y 739 habla de un Compendio de la Gramática Arabe, que, para el breve adelantamiento de sus discioulos compuso el Dr. D. Mariano Pizzi, Protesor Regio Matritense año 1780, y puntualiza que, además de esta fecha, aparecen en ella otras dos: 1783 (en el título árabe) y 1785 (en el colofón). Menciona, asimismo, otra redacción más completa de la misma obra. fechada en 1782. Y alude a una tercera versión - cuyo paradero desconoce-, fechada en 1784. Como se ve, todas estas gramáticas son de los mismos años que la de El Escorial.

Parecidas referencias encontramos en el artículo de Ron de la Bastida (pseudómino de Rodríguez-Moñino): "Los manuscritos árabes de Conde (1824)», Al-Andalus 21 (1956), 113-124, especialmente las páginas 119 , 123 y 124

Y en la Real Academia de la Historia se conserva otra gramática árabe de Pizzi, ésta en metro castellano.

(19) Véase lo que de su presunta explotación de ciertas personas para la composición de sus trabajos dicen Juan L. CARRILLO y M. a Paz TORRES en su estudio: libn al-Baytar y el arabismo español del XVIII. Edición trilingúe del prólogo de su «Kitab al-Chami», Benalmádena-Málaga, 1982. 